\title{
Assessment of burnout in medical students using the Maslach Burnout Inventory- Student Survey: a cross-sectional data analysis
}

Michael Obregon ${ }^{1 \dagger}$, Jessica Luo ${ }^{1 \dagger}$, Jarod Shelton ${ }^{1 *}+\mathbb{D}$, Terri Blevins ${ }^{2}$ and Martin MacDowell ${ }^{3}$

\begin{abstract}
Background: Medical student burnout can cause emotional and physical exhaustion and detachment. The objectives of this study were to evaluate burnout using the Maslach Burnout Inventory-Student Survey (MBI-SS), identify factors that may predict burnout, and assess wellness initiatives effectiveness at reducing burnout.

Methods: The MBI-SS was administered to all medical students (Classes 2019 to 2022) at the University of Illinois College of Medicine (UICOM) from February to May 2019. Factor analysis and internal consistency of the MBI-SS were assessed. Mean MSBI-SS subscale scores for burnout were calculated for cynicism (CY), emotional exhaustion (EE), and academic efficacy (AE). Multiple regression analysis was used to identify student factors that may predict burnout.

Results: A total of $273(21.6 \%)$ UICOM students completed the survey and $110(40.3 \%)$ respondents reported selfperceived burnout. MBI-SS subscale scores were significantly higher for $\mathrm{CY}$ and $\mathrm{EE}$, and significantly lower for AE in students who reported suffering from burnout versus students who did not report burnout. Mean \pm SD subscale scores for $C Y, E E$, and $A E$ in burnout students were $14.44 \pm 5.59,23.23 \pm 4.74$, and $24.81 \pm 5.35$, respectively. In comparison, mean $\pm S D$ subscale scores for $C Y, E E$, and $A E$ in non-burnout students were $7.59 \pm 5.16,14.96 \pm 5.71$, and $28.74 \pm 3.21$, respectively. Regression analysis denoted significant associations between burnout and being outof-phase in the curriculum, the effectiveness of wellness initiatives, and strength of motivation for medical school (SMMS) in both the two- and three-dimensional MBI-SS models. Gender was significantly associated with burnout in only the two-dimensional model.

Conclusions: Self-reported burnout in medical students at UICOM was validated using the MBI-SS. Being out-ofphase in the curriculum, being female, rating wellness initiatives as less effective, and demonstrating lower motivation for continued medical school education may be used as predictors of medical student burnout. This investigation may act as a guide for measuring burnout in medical student populations and how the implementation of wellness initiatives may ameliorate burnout.
\end{abstract}

Keywords: Medicine, Students, Burnout, Maslach, MBI-SS, Motivation, Wellness

\footnotetext{
* Correspondence: jarodshelton1@gmail.com

${ }^{+}$Michael Obregon, Jessica Luo and Jarod Shelton contributed equally to this work.

${ }^{1}$ University of Illinois College of Medicine at Rockford, 1601 Parkview Ave, Rockford, IL 61107, USA

Full list of author information is available at the end of the article
}

C C The Author(s). 2020 Open Access This article is licensed under a Creative Commons Attribution 4.0 International License, which permits use, sharing, adaptation, distribution and reproduction in any medium or format, as long as you give appropriate credit to the original author(s) and the source, provide a link to the Creative Commons licence, and indicate if changes were made. The images or other third party material in this article are included in the article's Creative Commons licence, unless indicated otherwise in a credit line to the material. If material is not included in the article's Creative Commons licence and your intended use is not permitted by statutory regulation or exceeds the permitted use, you will need to obtain permission directly from the copyright holder. To view a copy of this licence, visit http://creativecommons.org/licenses/by/4.0/ The Creative Commons Public Domain Dedication waiver (http://creativecommons.org/publicdomain/zero/1.0/) applies to the data made available in this article, unless otherwise stated in a credit line to the data. 


\section{Background}

Herbert Freudenberger first described burnout in 1974 as a 'state of mental and physical exhaustion caused by one's professional life [1]. The definition of burnout changes slightly depending on the population under investigation, yet, the underlying description explained by Freudenberger remains consistent, while its impact upon the health care system is ever evolving. The rate of selfreported burnout among physicians in the United States increased from 40 to 51\% from 2013 to 2017, respectively [2]. Healthcare practitioner burnout may be characterized as 'various degrees of emotional exhaustion, depersonalization and a low sense of personal accomplishment' [3]. Physician burnout can decrease the accuracy of medical diagnoses, impede effective patientphysician communication, and increase the number of unnecessary medical procedures [4]. The annual economic impact of physician burnout has been estimated at $\$ 3.4$ billion dollars with this loss expected to increase alongside worsening rates of burnout [5].

Numerous investigations have studied the origins of physician burnout and it has been reported that the phenomenon may begin manifesting as early as medical school $[6,7]$. In fact, some studies suggest that approximately half of all medical students may be suffering from burnout before residency $[8,9]$. The responsibilities of a medical student, in comparison to a resident or attending physician, are greatly limited due to their evolving knowledge base and clinical experience, nevertheless, medical students are expected to perform at a level that may seem unachievable. Corish estimated that the volume of medical knowledge has doubled every 73 days since 2010 [10]. Gradually, this new medical knowledge is integrated within the curriculum and students are expected to master the information for their United States Medical Licensing Examination (USMLE). The score a student receives on the USMLE, especially STEP 1, is directly correlated with their ability to matriculate in their desired specialty, and the stress associated with the examination has been shown to negatively impact a student's wellbeing [11].

Aside from the stressors of classroom and the board exams, burnout has been linked with loneliness, depression, isolation, an inability to relate to one's peers, and feelings of apathy and depersonalization [12]. Additionally, increased alcohol use/abuse, illicit drug use, and suicidal ideations have been associated with burnout in medical students [13-15]. These attributes have been shown to decrease the quality of care delivered to a patient and therefore, require immediate correction before a medical student is granted increased autonomy during residency.

Given the serious implications of medical student burnout, it is necessary to identify predictors that may influence the phenomenon. Acquiring a better understanding of the predictors of burnout may allow for resolutions to be developed that target the most severe causes. If the most significant causes are addressed, it may be possible to reduce the rate of burnout and improve the well-being of future physicians throughout their undergraduate and graduate medical education.

\section{Current study}

The purpose of this investigation was to evaluate medical student burnout using the Maslach Burnout Inventory-Student Survey (MBI-SS) within a single medical school system in the United States. The research questions this paper sought to address are as follows: (RQ1) Can the MBI-SS be used to predict burnout in medical school students; (RQ2) Are there any associations between burnout and demographic factors that can be used to identify students at risk for developing burnout; and (RQ3) Are the use of wellness initiatives sufficient for reducing burnout among medical students?

\section{Methods \\ Study design and setting}

The study was approved by the Internal Review Board (IRB) at the University of Illinois at Rockford (UI-Rockford). Medical students from each class (M1-M4 and $\mathrm{MD} / \mathrm{PhD}$ ), totaling 1359 students, at the University of Illinois College of Medicine (UICOM) were asked to complete the cross-sectional survey. UICOM has four distinct campuses: Chicago, Peoria, Rockford, and Urbana-Champaign. MD/PhD students and all students at Urbana-Champaign were excluded (95 students) from the final analysis due to low response rates of $<6 \%$ and $<$ $3 \%$, respectively. The study was conducted from February 2019 to May 2019. The survey was hosted on the web-based application, Google Forms. A nonprobability sampling method was used by sending several campus-wide emails to students requesting their voluntary participation. A non-probability sampling method was used to decrease the likelihood of selection bias for students who are less responsive to a single email. Four, \$25 apparel items were offered as an incentive to complete the survey. Students were randomly selected for the incentive. Strengthening the reporting of observational (STROBE) guidelines for observational studies were followed throughout. The first page of the survey contained a statement of consent, agreeing to be included in the study. All 273 respondents who started the survey consented and completed the survey. No students refused consent.

\section{Measures}

The survey (see Additional file 2) was a mix of demographic, career-oriented, medical specialty, MBI-SS, and 
SMMS questions. The 16-item MBI-SS is a validated tool used to measure burnout in student populations [16]. The MBI-SS (Mind Garden Inc., Menlo Park, CA) consists of three subscales to evaluate the different domains of burnout: emotional exhaustion (i.e. the draining of emotional resources because of demanding interpersonal contacts with others), cynicism (i.e. negative, callous, and cynical attitude towards the recipients of one's care or services), and academic efficacy (i.e. tendency to evaluate one's accomplishments with recipients negatively) [17]. Responses are provided on a 7point Likert scale with higher values referencing more frequent occurrences. Higher scores for $\mathrm{CY}$ and $\mathrm{EE}$ while lower scores for AE suggest burnout. Item 13 was deleted from the MBI-SS based on prior investigations finding it to be ambivalent and unsound [18-20].

The 15-item Strength of Motivation for Medical School questionnaire (SMMS) is a self-report tool that evaluates the strength of motivation medical students have for training in medical school. The SMMS consists of three subscales that evaluate different domains of motivation: willingness to sacrifice (i.e. the willingness of a student to sacrifice for his/her medical study), readiness to start (i.e. the readiness and will to enter/continue medical study), and persistence (i.e. the persistence in medical study in spite of unfriendly circumstances during or after the study [21]. Responses are provided on a 5 -point Likert scale and subscale scores can range from 5 to 25 . Higher values suggest greater motivation to continue training in medical school.

\section{Data analysis}

All data was exported from Google Survey to Excel v365 (Microsoft Corporation, Redmond, WA). All analyses were performed using SPSS v25 (IBM Corporation, Armonk, NY). Descriptive summary statistics were calculated for all student demographics. Normality of data was evaluated using the Shapiro-Wilk test. A $P$-value less than 0.05 was considered significant.

\section{MBI-SS score calculation}

Reverse scoring for the MBI-SS was performed as previously described [22]. Both two- and threedimensional burnout scores were calculated based on the subjective nature of burnout amongst healthcare professionals [23-25]. The conceptualization of burnout has been subjected to scrutiny over the years. Although the MBI remains the gold standard for measuring subjective burnout, respondents may report burnout differently using one of the three factors. Regardless of these differences, our report shows that burnout can be accurately predicted in our cohort using either the two factor or three factor model. Two calculation methods, the summation (SUM) and average (AVE) method, are two validated techniques to compare burnout scores between respondents. MBI-SS scores were calculated using each method to determine if self-perceived burnout differed using the Student's t-test for independent groups. The two-dimensional MBI-SS model is the addition of EE and $\mathrm{CY}$, while the three-dimensional model is the addition of all subscales, EE, CY, and AE. No significant difference was noted using either method when comparing subscale scores, in addition to the two- and threedimensional burnout score. MBI-SS scores reported herein were calculated as means \pm standard deviation (SD) using the SUM method.

\section{Internal consistency of MBI-SS using Cronbach's alpha}

Cronbach's alpha was used to calculate internal consistency of all MBI-SS items and subscales. Reliability scores of $\geq 0.5$ were considered acceptable with higher scores indicating greater internal consistency [26].

\section{Factor analysis of MBI-SS using correlation matrix}

Statistical data reduction and analysis was performed on the data to explain the correlation between the summated scores in the three subscales (EE, CY, and $\mathrm{AE}$ ) as previously described [20]. Items with a loading of greater than 0.40 were considered significant. Oblique rotation of the matrix in the factor analysis was performed to account for potential cross-loadings between the MBI-SS subscales. Oblique rotation of the matrix assumed that the 3 MBI-SS subscales were not independent. The analysis in the supplementary file (Additional file 1) shows there is no difference between both the two- and threedimensional burnout score models.

\section{Multiple regression of $\mathrm{MBI}-\mathrm{SS}$}

The association between demographic factors, educational debt, effectiveness of wellness initiatives, the SMMS toolkit, and MBI-SS scores were examined using a series of linear regression models. MBI-SS subscales, two-factor, and three-factor scores were coded as dependent variables. All variables entered the models and beta coefficients with $t$-values were outputted to assess correlations.

\section{SMMS score calculation}

Reverse scoring for the validated SMMS was performed as previously described [27]. SMMS subscales (sacrifice, readiness to start, and persistence) were summated to develop a three-dimensional model of motivation. Mean \pm SD of the summated SMMS score were reported. 


\section{Results}

The survey was completed by 273 out of 1264 (21.6\%) UICOM students. Response rates by student demographics are shown in Table 1.

A total of 107 (39.2\%) students reported self-perceived burnout. Internal reliability (Cronbach's alpha) coefficients of the MBI-SS subscales were 0.834 for EE, 0.769

Table 1 Student demographics, $n=273$

\begin{tabular}{|c|c|c|}
\hline Variable & $\mathrm{n}$ & $\%$ of respondents \\
\hline \multicolumn{3}{|l|}{ Campus } \\
\hline Chicago & 125 & 15.8 \\
\hline Rockford & 86 & 38.6 \\
\hline Peoria & 62 & 25.3 \\
\hline \multicolumn{3}{|l|}{ Year of Enrollment } \\
\hline M1 & 88 & 26.5 \\
\hline M2 & 54 & 16.3 \\
\hline M3 & 79 & 25.2 \\
\hline M4 & 52 & 18.2 \\
\hline \multicolumn{3}{|c|}{ Time Off Before Matriculation (in years) } \\
\hline 0 & 112 & 41.0 \\
\hline 1 & 77 & 28.2 \\
\hline 2 & 42 & 15.4 \\
\hline 3 & 17 & 6.2 \\
\hline 4 & 11 & 4.0 \\
\hline 5 & 7 & 2.6 \\
\hline$\geq 6$ & 7 & 2.6 \\
\hline \multicolumn{3}{|l|}{ Gender } \\
\hline Male & 112 & 40.9 \\
\hline Female & 158 & 57.7 \\
\hline No Response & 3 & 1.1 \\
\hline \multicolumn{3}{|l|}{ Age Group (in years) } \\
\hline $21-23$ & 57 & 20.9 \\
\hline $24-26$ & 144 & 52.7 \\
\hline $27-29$ & 51 & 18.7 \\
\hline $30-32$ & 13 & 4.8 \\
\hline $33-35$ & 3 & 1.1 \\
\hline$\geq 36$ & 3 & 1.1 \\
\hline \multicolumn{3}{|l|}{ Educational Debt (USD) } \\
\hline$\$ 0$ & 43 & 15.7 \\
\hline$\$ 1-\$ 100,000$ & 89 & 32.5 \\
\hline$\$ 100,000-\$ 200,000$ & 68 & 24.8 \\
\hline$\$ 200,000-\$ 300,000$ & 47 & 17.2 \\
\hline$\$ 300,000-\$ 400,000$ & 16 & 5.8 \\
\hline$\$ 400,000-\$ 500,000$ & 6 & 2.2 \\
\hline$\geq \$ 500,000$ & 1 & 0.4 \\
\hline TOTAL & 273 & 21.5 \\
\hline
\end{tabular}

UICOM medical student characteristics with response rate for $\mathrm{AE}$, and 0.858 for $\mathrm{CY}$. Minimum acceptable value for reliability coefficient was 0.5 with values greater than 0.75 being preferable [26]. Statistical significance $(P$ value $<0.003)$ was identified between self-perceived burnout and non-burnout students in all MBI-SS items, in addition to the three subscales. Mean \pm SD for all MBI-SS items and subscale scores with reliability coefficients are listed in Table 2.

To assess the MBI-SS scale items regarding the current study population, factor analyses were run and item loadings were comparable to prior publications using the 15-item MBI-SS [19, 24, 25]. All items were significant. Also, correlations between the MBI-SS subscales were similar to prior publications (See Additional file 1 for factor analysis details).

\section{Student demographics as predictors of burnout}

MBI-SS subscale scores were calculated for student demographics, effect of burnout on desired specialty, and awareness of wellness initiatives (Table 3). High EE, $\mathrm{CY}$, and $\mathrm{AE}$ subscale scores were assessed to determine the percent of student demographics affected by high levels of burnout, using one SD above the mean for $\mathrm{EE}$ and $\mathrm{CY}$ and one $\mathrm{SD}$ below the mean for $\mathrm{AE}$ as indicators of severe burnout. Significance was identified for selfperceived burnout between years of enrollment ( $P$ value $=0.005)$ gender $(P$-value $=0.001)$, and effect of desired specialty $(P$-value $=0.001)$. No significance was noted for self-perceived burnout between campus ( $P$ value $=0.177), \quad$ ethnicity $\quad(P$-value $=0.062), \quad$ having children $(P$-value $=0.050)$, being religious $/$ spiritual $(P$ value $=0.162)$, and awareness of wellness initiatives $(P$-value $=0.362)$.

Multiple regression analysis of the two- and threedimensional MBI-SS models are shown in Table 4. The independent variables $($ Model 1$)$, out-of-phase $(P$-value $=$ $0.002)$ in the curriculum, gender $(P$-value $=0.035)$, the effectiveness of wellness initiatives $(P$-value $=0.006)$, and the SMMS toolkit $(P$-value $=0.001)$, were significantly associated with the two-dimensional MBI-SS model. Being out-of-phase $(B=-13.3)$ in the curriculum, rating the wellness initiatives as effective $(B=-2.8)$, and high ratings of the SMMS toolkit $(B=-0.5)$ were negatively associated with two-dimensional MBI-SS model. Gender $(B=3.7)$, specifically being female, was positively associated with two-dimensional MBI-SS model. The independent variables $($ Model 2$)$, out-of-phase $(P$-value $=$ 0.001 ) in the curriculum, the effectiveness of wellness initiatives $(P$-value $=0.048)$, and the SMMS toolkit $(P$ value $=0.001)$, were significantly associated with the three-dimensional MBI-SS model. All variables, being out-of-phase $(B=-11.7)$ in the curriculum, rating the wellness initiatives as effective $(B=-1.9)$, and high 
Table 2 Descriptive statistics of MBI-SS with internal consistency, $n=273$

\begin{tabular}{|c|c|c|c|c|}
\hline & Burnout & Non-Burnout & $P$-Value ${ }^{a}$ & Cronbach's Alpha $^{\mathrm{b}}$ \\
\hline Emotional Exhaustion & $23.23 \pm 4.74$ & $14.96 \pm 5.71$ & 0.001 & 0.834 \\
\hline ITEM 1 & $4.59 \pm 1.09$ & $2.69 \pm 1.40$ & 0.001 & 0.687 \\
\hline ITEM 2 & $5.0 \pm 1.12$ & $3.62 \pm 1.56$ & 0.001 & 0.690 \\
\hline ITEM 3 & $4.91 \pm 1.27$ & $3.60 \pm 1.59$ & 0.001 & 0.687 \\
\hline ITEM 4 & $4.11 \pm 1.36$ & $2.57 \pm 1.33$ & 0.001 & 0.686 \\
\hline ITEM 5 & $4.64 \pm 1.13$ & $2.49 \pm 1.42$ & 0.001 & 0.682 \\
\hline Academic Efficacy & $24.81 \pm 5.35$ & $28.74 \pm 3.21$ & 0.001 & 0.769 \\
\hline ITEM 1 & $4.58 \pm 1.29$ & $5.18 \pm 0.97$ & 0.001 & 0.723 \\
\hline ITEM 2 & $3.66 \pm 1.52$ & $4.25 \pm 1.37$ & 0.002 & 0.725 \\
\hline ITEM 3 & $4.10 \pm 1.55$ & $4.82 \pm 1.16$ & 0.001 & 0.722 \\
\hline ITEM 4 & $4.13 \pm 1.51$ & $4.91 \pm 1.18$ & 0.001 & 0.730 \\
\hline ITEM 5 & $4.77 \pm 1.14$ & $5.17 \pm 0.88$ & 0.003 & 0.724 \\
\hline ITEM 6 & $3.65 \pm 1.25$ & $4.47 \pm 1.21$ & 0.001 & 0.725 \\
\hline Cynicism & $14.44 \pm 5.59$ & $7.59 \pm 5.16$ & 0.001 & 0.858 \\
\hline ITEM 1 & $3.86 \pm 1.77$ & $1.75 \pm 1.47$ & 0.001 & 0.681 \\
\hline ITEM 2 & $4.22 \pm 1.61$ & $2.34 \pm 1.53$ & 0.001 & 0.679 \\
\hline ITEM 3 & $3.81 \pm 1.67$ & $2.03 \pm 1.70$ & 0.001 & 0.680 \\
\hline ITEM 4 & $2.54 \pm 1.81$ & $1.51 \pm 1.48$ & 0.001 & 0.725 \\
\hline
\end{tabular}

Descriptive statistics of MBI-SS with internal consistency, $n=273 .{ }^{a}$ Independent Student's t-test for significance and a $P$-value $<0.05$ was considered significant. ${ }^{\mathrm{b}}$ Cronbach's alpha evaluated internal consistency and a value $>0.50$ was considered acceptable

ratings of the SMMS toolkit $(B=-0.3)$ were negatively associated with three-dimensional MBI-SS model.

Multiple regression analysis of MBI-SS subscale scores was evaluated to determine if any significance in the two- and three-dimensional MBI-SS models were due to individual or a combination of subscale scores (Table 5). The independent variables (Model 3), out-of-phase $(P$-value $=0.006)$ in the curriculum, gender $(P$-value $=$ $0.017)$, the effectiveness of wellness initiatives $(P$-value $=$ $0.016)$, and the SMMS toolkit $(P$-value $=0.001)$, were significantly associated with the EE subscale. Negative associations between being out-of-phase $(B=-6.5)$ in the curriculum, rating the wellness initiatives as effective $(B=$ -1.3), and high ratings of the SMMS toolkit $(B=-0.2)$ were noted with the EE subscale. Again, gender $(B=2.3)$, especially being female, was positively associated with the EE subscale. The independent variables (Model 4), the effectiveness of wellness initiatives $(P$-value $=0.024)$ and the SMMS toolkit $(P$-value $=0.001)$, were significantly associated with the AE subscale. Both rating the wellness initiatives as effective $(B=1.1)$ and high ratings of the SMMS toolkit $(B=0.2)$ were positively associated with the $A E$ subscale. The independent variables (Model 5), out-ofphase $(P$-value $=0.002)$ in the curriculum, the effectiveness of wellness initiatives $(P$-value $=0.005)$, and the SMMS toolkit $(P$-value $=0.001)$, were significantly associated with the $C Y$ subscale. Being out-of-phase $(B=-6.8)$ in the curriculum, rating the wellness initiatives as effective $(B=-2.8)$, and high ratings of the SMMS toolkit $(B=-0.3)$ were negatively associated with the $C Y$ subscale.

\section{Discussion}

In the current study, burnout was described as 'feeling exhausted because of study demands, having a cynical and detached attitude toward one's study, and feeling incompetent as a medical student. High values for EE and $\mathrm{CY}$ while low values for $\mathrm{AE}$ were considered consistent with burnout. The main findings of this study were the following: the MBI-SS is a validated tool that may be used in place of the MBI- Health Care Survey (HSS) to assess medical student burnout; student demographics like gender, year in the curriculum, and a student's view on wellness initiatives can be used to identify individuals at risk for developing burnout. A new demographic factor that has not been described in the current literature as associated with medical student burnout, out-ofphase medical students, should be considered in assessing medical students at risk for developing burnout.

\section{MBI-SS prediction of burnout in medical students}

Significance between burnout versus non-burnout students was noted for all MBI-SS items, subscales, twoand three-dimensional models. Internal consistency measured using Cronbach's Alpha was equal or higher than previous burnout studies using the MBI-SS [16, 28, 
Table $3 \mathrm{MBI}$-SS subscale scores and association between self-reported burnout, $n=273$

\begin{tabular}{|c|c|c|c|c|c|c|c|c|}
\hline & \multicolumn{2}{|c|}{ Emotional Exhaustion } & \multicolumn{2}{|l|}{ Cynicism } & \multicolumn{2}{|c|}{ Academic Efficacy } & \multirow[b]{2}{*}{$\begin{array}{l}\text { Burnout } \\
\text { n (\%) }\end{array}$} & \multirow[b]{2}{*}{$\begin{array}{l}X^{2} \text {-statistic }{ }^{\mathrm{b}} \\
(P \text {-value })\end{array}$} \\
\hline & Mean \pm SD & $\begin{array}{l}\text { High EE } \\
\text { score } \mathrm{n}(\%)^{\mathrm{a}}\end{array}$ & Mean \pm SD & $\begin{array}{l}\text { High CY } \\
\text { score } \mathrm{n}(\%)^{\mathrm{a}}\end{array}$ & Mean \pm SD & $\begin{array}{l}\text { High AE } \\
\text { score } n(\%)^{a}\end{array}$ & & \\
\hline All responses $(n=273)$ & $18.3 \pm 6.67$ & $23(8.4)$ & $10.41 \pm 6.29$ & $23(8.4)$ & $27.11 \pm 5.34$ & $27(9.9)$ & $107(39.2)$ & \\
\hline \multicolumn{9}{|l|}{ Campus } \\
\hline Chicago $(n=125)$ & $18.56 \pm 7.12$ & $13(10.4)$ & $10.86 \pm 6.11$ & $16(12.8)$ & $27.4 \pm 5.4$ & $13(10.4)$ & $56(44.8)$ & $3.46(0.177)$ \\
\hline Peoria $(n=59)$ & $17.55 \pm 6.45$ & $3(5.1)$ & $9.26 \pm 5.84$ & $1(1.7)$ & $26.66 \pm 6.86$ & $8(13.6)$ & $33(38.8)$ & \\
\hline Rockford $(n=85)$ & $18.48 \pm 6.19$ & $7(8.2)$ & $10.67 \pm 5.78$ & $6(7.1)$ & $27.03 \pm 5.45$ & $6(7.1)$ & $18(30.5)$ & \\
\hline \multicolumn{9}{|l|}{ Year of enrollment } \\
\hline M1 $(n=88)$ & $17.39 \pm 6.44$ & $4(4.6)$ & $8.67 \pm 6.07$ & $7(8)$ & $27.77 \pm 4.68$ & $6(6.8)$ & $26(29.5)$ & $12.66(\mathbf{0 . 0 0 5 )}$ \\
\hline $\mathrm{M} 2(n=51)$ & $19.3 \pm 6.86$ & $4(7.8)$ & $10.91 \pm 5.9$ & $2(3.9)$ & $25.65 \pm 6.1$ & $10(19.6)$ & $23(45.1)$ & \\
\hline $\mathrm{M} 3(n=78)$ & $20.1 \pm 6.04$ & $9(11.5)$ & $12.46 \pm 6.40$ & $10(12.8)$ & $26.68 \pm 5.24$ & $7(9)$ & $42(53.8)$ & \\
\hline M4 $(n=52)$ & $16.13 \pm 7.08$ & $6(11.6)$ & $9.85 \pm 5.89$ & $4(7.7)$ & $28.17 \pm 5.47$ & $4(7.7)$ & $16(30.8)$ & \\
\hline \multicolumn{9}{|l|}{ Gender } \\
\hline Male $(n=110)$ & $17.22 \pm 6.63$ & $6(5.5)$ & $9.81 \pm 6.16$ & $7(6.4)$ & $27.63 \pm 5.24$ & $8(7.3)$ & $30(27.3)$ & $11.69(\mathbf{0 . 0 0 1 )}$ \\
\hline Female $(n=156)$ & $19.07 \pm 6.68$ & $17(10.9)$ & $10.8 \pm 6.3$ & $15(9.6)$ & $26.7 \pm 5.46$ & 19 (12.2) & $75(48.1)$ & \\
\hline \multicolumn{9}{|l|}{ Ethnicity } \\
\hline Asian $(\mathrm{n}=59)$ & $18.86 \pm 7.14$ & $6(15.4)$ & $11.02 \pm 6.67$ & $6(15.4)$ & $25.76 \pm 5.73$ & $10(25.6)$ & $27(45.8)$ & $8.97(0.062)$ \\
\hline Black/AA $(n=12)$ & $16.75 \pm 8.79$ & $2(5.1)$ & $10.17 \pm 8.5$ & $3(7.7)$ & $27.92 \pm 4.68$ & $1(2.6)$ & $5(41.7)$ & \\
\hline Hispanic/Mexican $(n=22)$ & $18 \pm 6$ & $1(2.6)$ & $11.45 \pm 4.62$ & $1(2.6)$ & $27.27 \pm 5.4$ & $1(2.6)$ & $7(31.8)$ & \\
\hline White $(n=166)$ & $18.13 \pm 6.55$ & $13(33.3)$ & $10.06 \pm 6.2$ & $13(33.3)$ & $27.7 \pm 5.05$ & $12(30.8)$ & $58(34.9)$ & \\
\hline Other $(n=14)$ & $19.79 \pm 5.62$ & $1(2.6)$ & $11 \pm 5.62$ & $0(0)$ & $24.93 \pm 6.63$ & $3(7.7)$ & $10(71.4)$ & \\
\hline \multicolumn{9}{|l|}{ Children } \\
\hline Yes $(n=10)$ & $14.54 \pm 5.8$ & $0(0)$ & $7.91 \pm 5.56$ & $1(10)$ & $27.91 \pm 3.88$ & $0(0)$ & $1(10)$ & $3.84(0.050)$ \\
\hline No $(n=259)$ & $18.46 \pm 6.68$ & $23(8.9)$ & $10.54 \pm 6.27$ & $22(8.5)$ & $27.08 \pm 5.4$ & $27(10.4)$ & $106(40.9)$ & \\
\hline \multicolumn{9}{|l|}{ Religion/Spiritual } \\
\hline Yes $(n=122)$ & $17.96 \pm 6.88$ & $13(10.7)$ & $10.29 \pm 6.2$ & $11(9)$ & $27.3 \pm 5.74$ & $14(11.5)$ & $44(36.1)$ & $1.96(0.162)$ \\
\hline No $(n=69)$ & $18.67 \pm 5.76$ & $5(7.2)$ & $10.74 \pm 5.9$ & $6(8.7)$ & $26.93 \pm 4.82$ & $5(7.25)$ & $32(46.4)$ & \\
\hline \multicolumn{9}{|l|}{ Effect of desired specialty } \\
\hline Yes $(n=84)$ & $22.38 \pm 5.75$ & $19(22.6)$ & $13.94 \pm 5.55$ & $0(0)$ & $25.07 \pm 5.75$ & $14(16.7)$ & $60(71.4)$ & $50.63(\mathbf{0 . 0 0 1 )}$ \\
\hline No $(n=184)$ & $16.4 \pm 6.24$ & $4(2.2)$ & $8.76 \pm 5.9$ & $7(3.8)$ & $28.08 \pm 4.91$ & $13(7.1)$ & $47(25.5)$ & \\
\hline \multicolumn{9}{|l|}{ Awareness of wellness initiatives } \\
\hline Yes $(n=229)$ & $18.23 \pm 0.32$ & $20(8.7)$ & $10.11 \pm 0.31$ & $0(0)$ & $27.21 \pm 0.35$ & $24(10.5)$ & $88(38.4)$ & $0.83(0.362)$ \\
\hline No $(n=39)$ & $18.44 \pm 6.74$ & $3(7.7)$ & $12 \pm 7.4$ & $9(23.1)$ & $26.79 \pm 5.02$ & $3(7.7)$ & $18(46.2)$ & \\
\hline
\end{tabular}

MBI-SS factor analysis loadings, $n=273$. Items with loading of $\geq 0.4$ were considered significant

MBI-SS subscale correlations, $\mathrm{n}=273$

${ }^{\mathrm{a}}$ Burnout population mean $\pm 1 \mathrm{SD} .{ }^{\mathrm{b}}$ Chi-square test for independence. ${ }^{\mathrm{c}} P$-value $<0.05$ considered significant

29]. Several MBI surveys are available to measure burnout in different populations. The Human Services Survey is the most widely used MBI version and primarily examines burnout in health professions, i.e. physicians, nurses, social workers, etc. [22]. Most investigations examining burnout in medical students have used the MBI-HSS given a student's responsibility of providing care to patients [30]. The MBI-SS, which is an adaptation of the General Survey, was used in this investigation to examine how the rigors of medical education influence burnout, regardless of their interactions with patients.

Our population was comprised of both preclinical and clinical year medical students who had differing levels of experience interacting with patients. Additionally, as student-doctors, the main goal of medical students is to obtain medical knowledge, and apply that knowledge to patients. Conversely, health care professionals are indeed lifelong learners, yet burnout may not stem from their studies, but rather from the rigors of their job. For 
Table 4 Regression analysis of MBI-SS two- and three-dimensional models for continuous variables, $n=273$

\begin{tabular}{|c|c|c|c|c|c|c|}
\hline & \multicolumn{3}{|l|}{ Two-Dimensional } & \multicolumn{3}{|c|}{ Three-Dimensional } \\
\hline & $\begin{array}{l}\text { Unstandardized } \\
\text { beta coefficient }\end{array}$ & $\mathrm{t}$ & $\overline{P \text {-value }}$ & $\begin{array}{l}\text { Unstandardized } \\
\text { beta coefficient }\end{array}$ & $\mathrm{t}$ & P-value \\
\hline Year of enrollment & -1.107 & -1.007 & 0.316 & -0.234 & -0.246 & 0.806 \\
\hline Campus & 0.507 & 0.446 & 0.656 & -0.569 & -0.58 & 0.563 \\
\hline Out-of-Phase & -13.308 & -3.184 & 0.002 & -11.676 & -3.235 & 0.001 \\
\hline Time off before matriculation & 2.896 & 1.371 & 0.172 & 1.103 & 0.605 & 0.546 \\
\hline Gender & 3.713 & 2.121 & 0.035 & 2.601 & 1.721 & 0.087 \\
\hline Age & -0.053 & -0.122 & 0.903 & 0.234 & 0.628 & 0.531 \\
\hline Relationship status & -0.249 & -0.111 & 0.912 & -1.981 & -1.025 & 0.307 \\
\hline Children currently & 1.474 & 0.306 & 0.76 & 0.671 & 0.162 & 0.872 \\
\hline Religious/Spiritual & 0.794 & 0.424 & 0.672 & 0.783 & 0.484 & 0.629 \\
\hline Educational debt & 1.463 & 1.247 & 0.214 & 0.762 & 0.752 & 0.453 \\
\hline Effectiveness of wellness initiatives & -2.82 & -2.808 & 0.006 & -1.726 & -1.991 & 0.048 \\
\hline SMMS Toolkit & -0.517 & -6.322 & 0.001 & -0.316 & -4.245 & 0.001 \\
\hline
\end{tabular}

The two- and three-dimensional models had a R-Squared of 0.226 and 0.153 , respectively. Both models were significant $(P$-value $<0.001)$

example, Friedberg et al. noted that physician's interactions with electronic health records was associated with decreased job satisfaction in some survey respondents [31]. So, yes medical students do have their share of administrative work, but their focus remains gaining knowledge to be competent clinicians, and to do well on exams.

\section{Factors to predict burnout in medical students}

Year of enrollment was found to be associated with burnout. Additionally, the rate of burnout increased until the M3 year and then sharply decreasing during the M4 year. These findings are similar to previous studies looking at the association between year in medical school and perceived burnout [14, 32]. We hypothesize that this association for second-year medical students is related to their preparation for the USMLE Step 1 Board Exam. Historically, the Step 1 score has a high degree of impact upon a medical student's ability to Match in a competitive specialty or at a competitive program [33] For third year medical students, their focus is centered on NBME Clerkship Examinations, USMLE Step 2 CS and CK, and scheduling sub-internship electives. Again, all these aspects of the medical education impact an individual's ability to Match in their desired specialty or desired program. Most M4 students, at the time of the study were finished with residency interviews and were awaiting their match results. So, it is likely that much of

Table 5 Regression analysis of MBI-SS subscales for continuous variables, $n=273$

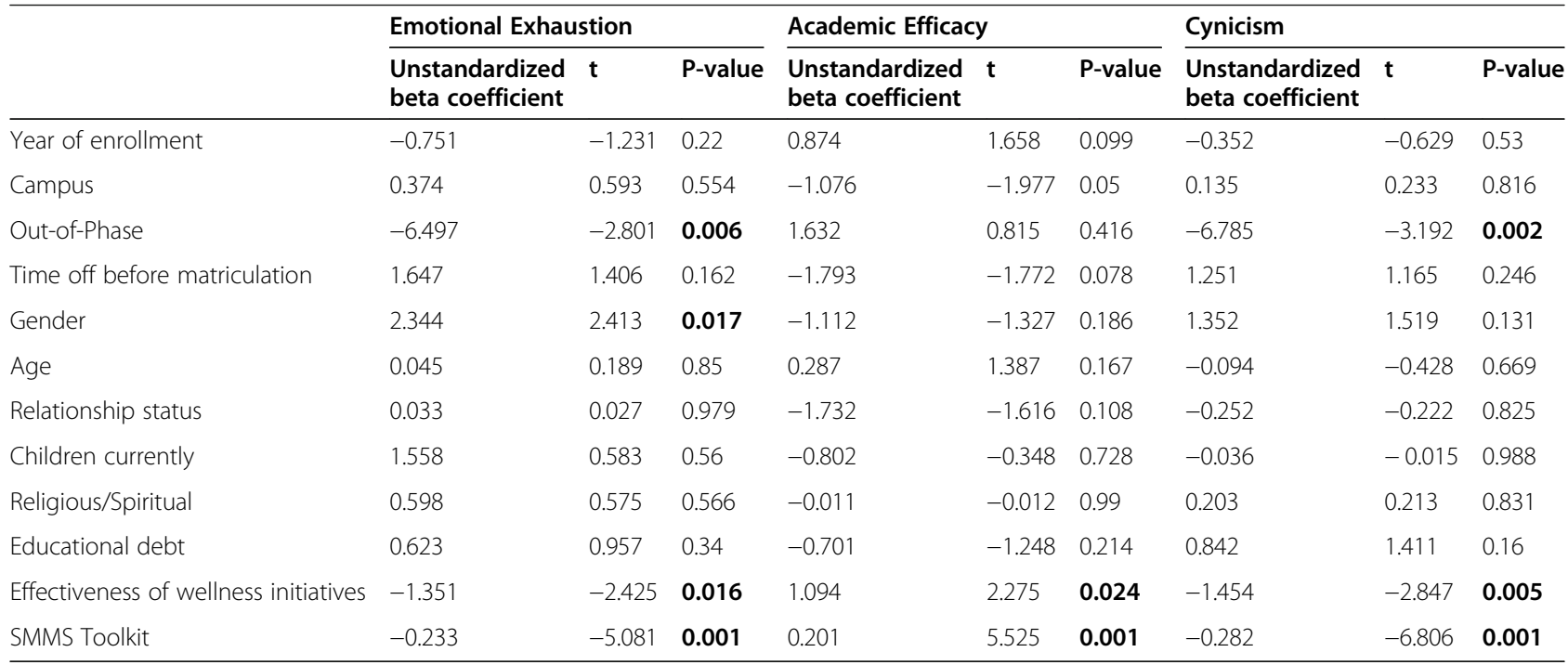

The EE, CY, and AE models had an R-Squared of $0.191,0.227,0.210$. All models were significant $(P$-value $<0.001)$ 
the stress and anxiety had diminished as M4 students were looking at transitioning into residency and finalizing graduation requirements.

A second demographic factor associated with burnout in our study population was gender, specifically being female in the two-dimensional model and EE MBI-SS subscale. Higher rates of EE in females have been previously shown and with the two-dimensional model only accounting for $\mathrm{EE}$ and $\mathrm{CY}$, it is not surprising that the model be used as a predictor of burnout between genders [34].

Yet, this area has proved to be inconsistent, as other studies have found no association between burnout and gender [19, 35, 36]. Studies looking at gender differences in physicians have suggested some of the following: women are more likely to report emotional exhaustion; women may be more likely to report burnout versus their male counter parts; or age may influence expression of burnout, as older physicians are less likely to express their burnout [37-40].

A third demographic factor associated with burnout in our study, are students who are out of phase in their medical education. An out of phase student is any individual that takes a leave of absence during their medical education. This may due to academic reasons, personal reasons, or medical reasons. Students who were out-ofphase in the curriculum were more likely to report burnout in the two- and three-dimensional model, and EE and CY MBI-SS subscales. Lower scores in the AE MBISS subscale were not predictive of burnout. This was likely due to a student's decision to continue their medical education regardless of how many additional years they need to graduate. At our institution, M1 and M2 students have classes scheduled for them, so if for whatever reason they do not complete their required course, they may have to wait until that specific course is offered during the following cycle. For M3 and M4 students, NBME Shelf Examination, USMLE Step Examinations, and residency application deadlines create constraints on the ability for a student to take time off. The authors hypothesize that these constraints may influence burnout in this population of medical students.

\section{Wellness initiatives}

Students that reported that the wellness initiatives were effective had lower levels of burnout in all categories. This finding provides strong evidence that implementing effective wellness initiatives may be sufficient for reducing burnout. Across UICOM, the services students participated the most in were health services (17.1\%), meditation (16.6\%), and others (8.3\%), such as dog therapy, aromatherapy, and art therapy. Other wellness initiatives that students reported as beneficial were access to mental health resources on campus. Studies have shown participation in various interventions can reduce stress and depression [36]. Yet, one aspect that is important is to ensure that students are aware of these services, and that services like mental health services remain anonymous. For example, Dyrbye et al. showed that as many as two thirds of medical students may not seek help due to perceived stigmas associated with doing so [41].

\section{Strength of motivation for medical students}

Students who scored higher on the SMMS reported less burnout. The authors hypothesize that this may be related to a student's interest in a given specialty. Essentially, they find school work in that area of medicine more rewarding. In our study, students who reported burnout were more likely to consider switching their medical specialties to one they considered 'less desirable'. This could have serious implications for any specialty that is experiencing decreased residency matriculation, such as general surgery [3]. Of note though, the level of SMMS persistence subscale was similar between both burnout and non-burnout students. This observation may be due to a student's determination to continue their education regardless of their level of burnout. With the high cost of medical education, and limited options with an incomplete medical degree, students push to simply complete their medical education and enter an area of medicine that is less competitive and of less interest to them.

\section{Survey response}

$21.6 \%$ of eligible students at the University of Illinois medical school responded to the survey. We acknowledge a degree of selection bias, as our data was gathered via a web-based survey tool. We hypothesize survey fatigue occurred among our study population for at least two reasons. One reason is associated with the number of emails students received daily. Students at the University of Illinois receive emails from the College of Medicine, University of Illinois at Chicago (university wide emails), and site-specific notifications (Chicago, Peoria, Rockford, and Champaign-Urbana). A second aspect associated with the response rate is more specific to each class year. When the survey was sent out, second year medical students were studying for the USMLE Step 1 examination. Third year medical students were focused on scheduling away rotations/sub-internships, USLME Step 2 CK and CS examinations. Lastly, fourth year medical students were focused on Match Day and their subsequent transition into residency.

\section{Limitations}

The study was cross-sectional by design and the relationships described are only associations and merely 
suggest a potential causal relationship between burnout and student demographics. The survey period may have influenced perceived level of burnout due to the high stress board examinations and upcoming away rotation applications experienced by M2 and M3 students, respectively. A response rate of $21.6 \%$ may suggest that the study was selectively completed by students who possessed a strong opinion about burnout and are not reflective of the entire UICOM medical student population [42, 43]. Lastly, co-morbidities such as mental and physical health, substance abuse, and uncontrollable life events were not assessed in the survey, which have been shown to influence burnout in the medical profession [13, 15, 44, 45].

\section{Conclusion}

The 15-item MBI-SS is a validated tool that can assess burnout in medical students. Burnout among UICOM medical students was slightly less than reported national averages. Student demographics: gender, year of enrollment, and being out-of-phase in the curriculum, may be used to identify at-risk groups susceptible to burnout. The implementation of effective wellness initiatives may be sufficient for ameliorating burnout among medical students. We recommend burnout be longitudinally assessed once a year in all medical students to determine the effectiveness of wellness initiatives and make modifications as appropriate. Burnout is a deleterious issue that can negatively impact the healthcare community. Early identification and resolution of the phenomenon can help improve the health outcomes of patients receiving care from medical students and residents progressing through their education.

\section{Supplementary information}

Supplementary information accompanies this paper at https://doi.org/10. 1186/s12909-020-02274-3.

Additional file 1.

Additional file 2.

\section{Abbreviations}

UICOM: University of Illinois College of Medicine; UI-Rockford: University of Illinois College of Medicine at Rockford; MS\#: Medical Student Year 1-4; MBISS: Maslach Burnout Inventory-Student Survey; EE: Emotional Exhaustion; CY: Cynicism; AE: Academic Efficacy; SMMS: Strength of Motivation for Medical School; IRB: Internal Review Board; SD: Standard Deviation; B: Unstandardized Beta Coefficient

\section{Acknowledgements}

The authors would like to acknowledge all the students who took the time to complete the survey and thank Dr. Olle Ten Cate for permission to reproduce and distribute the SMMS questionnaire.

\section{Authors' contributions}

$M O, J L, J S, T B$, and $M M$ were involved in the conception and design of the study. MO, JL, and JS collected the data. MO, JL, JS, and MM analyzed and interpreted the data. MO, JL, and JS prepared the manuscript. TB and MM made substantial contributions to revise the manuscript. All authors read and approved the final manuscript.

\section{Funding}

This research was supported by a Clinical, Educational, and Community Health Research grant from the Office of Research at UI-Rockford. The funders provided monetary support for the purchase of the burnout inventory tool, poster printing, conference, and travel expenses.

\section{Availability of data and materials}

Data is freely available on reasonable request.

\section{Ethics approval and consent to participate}

This study was approved by the IRB at UI-Rockford. All respondents provided written agreement to participate in the study and were given the option to withdrawal at any time.

\section{Consent for publication}

Our findings have been reviewed by our research committee and we have obtained consent for publication.

\section{Competing interests}

The authors declare that they have no competing interests.

\section{Author details}

${ }^{1}$ University of Illinois College of Medicine at Rockford, 1601 Parkview Ave, Rockford, IL 61107, USA. ${ }^{2}$ Research Assistant Professor and Assistant Dean for Student Affairs and Academic Progress, University of Illinois College of Medicine at Rockford, Rockford, IL, USA. ${ }^{3}$ Research Professor and Associate Director Health Professions Education, Department of Family Medicine, National Center for Rural Health Professions, University of Illinois College of Medicine at Rockford, Rockford, IL, USA.

Received: 27 February 2020 Accepted: 1 October 2020

Published online: 21 October 2020

\section{References}

1. Freudenberger HJ. Staff Burn-Out. J Soc Issues. 2010;30(1):159-65.

2. Reith TP. Burnout in United States healthcare professionals: a narrative review. Cureus. 2018;10(12):1-9.

3. Yang Y, Li J, Wu X, Wang J, Li W, Zhu Y, et al. Factors influencing subspecialty choice among medical students: a systematic review and meta-analysis. BMJ Open. 2019;9(3):1-12.

4. West CP, Dyrbye LN, Erwin PJ, Shanafelt TD. Interventions to prevent and reduce physician burnout: a systematic review and meta-analysis. Lancet. 2016;388(10057):2272-81. https://doi.org/10.1016/S0140-6736(16)31279-X.

5. Han S, Shanafelt TD, Sinsky CA, Awad KM, Dyrbye LN, Fiscus LC, et al. Estimating the Attributable Cost of Physician Burnout in the United States. Ann Intern Med. 2019;170(11):784 Available from: http://annals.org/article. aspx?doi=10.7326/M18-1422.

6. Ishak W, Nikravesh R, Lederer S, Perry R, Ogunyemi D, Bernstein C. Burnout in medical students: a systematic review. Clin Teach. 2013;10(4):242-5.

7. Chunming WM, Harrison R, Maclntyre R, Travaglia J, Balasooriya C. Burnout in medical students: a systematic review of experiences in Chinese medical schools. BMC Med Educ. 2017;17(1):1-11.

8. Cook AF, Arora VM, Rasinski KA, Curlin FA, Yoon JD. The prevalence of medical student mistreatment and its association with burnout. Acad Med. 2014:89(5):749-5.

9. Enoch L, Chibnall JT, Schindler DL, Slavin SJ. Association of medical student burnout with residency specialty choice. Med Educ. 2013;47(2):173-81.

10. Corish B. Medical knowledge doubles every few months; how can clinicians keep up? [Internet]. Elsevier Connect. 2018 [cited 2020Jan2]. Available from: https://www.elsevier.com/connect/medical-knowledge-doubles-every-fewmonths-how-can-clinicians-keep-up.

11. Gauer JL, Jackson JB. The association of USMLE Step 1 and Step 2 CK scores with residency match specialty and location. Med Educ Online. 2017;22(1): 1358579 .

12. Silva V, Costa P, Pereira I, Faria R, Salgueira AP, Costa MJ, et al. Depression in medical students: insights from a longitudinal study. BMC Med Educ. 2017; 17(1):184-9. 
13. Jackson ER, Shanafelt TD, Hasan O, Satele DV, Dyrbye LN. Burnout and alcohol abuse/dependence among U.S. medical students. Acad Med. 2016; 91(9):1251-6.

14. Elkins $C$, Kyle P, Germain LJ. Burnout and depression in MS1 and MS3 years: a comparison of cohorts at one medical school. Fam Med. 2017;49(6):1-4.

15. Rotenstein LS, Ramos MA, Torre M, Bradley Segal J, Peluso MJ, Guille C, et al. Prevalence of depression, depressive symptoms, and suicidal ideation among medical students a systematic review and meta-analysis. JAMA. 2016;316(21):2214-36.

16. Shi Y, Gugiu PC, Crowe RP, Way DP. A Rasch analysis validation of the Maslach burnout inventory-student survey with preclinical medical students. Teach Learn Med. 2019;31(2):154-69. https://doi.org/10.1080/ 10401334.2018.1523010.

17. Maslach C, Jackson SE. The measurement of experienced burnout. J Organ Behav. 1981:2(2):99-113.

18. Schaufeli WB, Martínez IM, Pinto AM, Salanova M, Bakker AB. Burnout and engagement in university students a cross-national study. Journal of crosscultural psychology. J Cross-Cult Psychol. 2002;33(5):464-81.

19. Galán F, Sanmartín A, Polo J, Giner L. Burnout risk in medical students in Spain using the Maslach burnout inventory-student survey. Int Arch Occup Environ Health. 2011;84(4):453-9.

20. Wickramasinghe ND, Dissanayake DS, Abeywardena GS. Clinical validity and diagnostic accuracy of the Maslach burnout inventory-student survey in Sri Lanka. Health Qual Life Outcomes. 2018;16(1):1-10.

21. Nieuwhof MGH, ThJ ten Cate O, Oosterveld P, Soethout MB. Measuring strength of motivation for medical school. Med Educ Online. 2004;9(1):4355.

22. Maslach C, Jackson SE, Leiter M. The Maslach burnout inventory manual 3rd edition. In: Maslach Burnout Inventory; 1997.

23. Poghosyan L, Aiken LH, Sloane DM. Factor structure of the Maslach burnout inventory: an analysis of data from large scale cross-sectional surveys of nurses from eight countries. Int J Nurs Stud. 2009;46(7):894-902.

24. Mészáros V, Ádám S, Szabõ M, Szigeti R, Urbán R. The bifactor model of the maslach burnout inventory-human services survey (MBI-HSS) - an alternative measurement model of burnout. Stress Heal. 2014;30(1):82-8.

25. Pérez-Mármol JM, Brown T. An examination of the structural validity of the Maslach Burnout Inventory-Student Survey (MBI-SS) using the rasch measurement model. Heal Prof Educ. 2019;5(3):259-74.

26. Taber KS. The Use of Cronbach's Alpha When Developing and Reporting Research Instruments in Science Education. Res Sci Educ. 2017;48(6):127396.

27. Leibach G, Stern M. Critical synthesis package: Strength of Motivation for Medical School—Revised (SMMS-R) questionnaire. MedEdPORTAL Publications; 2013. https://doi.org/10.15766/mep_2374-8265.9645

28. Portoghese I, Leiter MP, Maslach C, Galletta M, Porru F, D'Aloja E, et al. Measuring burnout among university students: Factorial validity, invariance, and latent profiles of the Italian Version of the Maslach Burnout Inventory Student Survey (MBI-SS). Front Psychol. 2018;9(NOV):1-9.

29. Dos Santos Boni RA, Paiva CE, De Oliveira MA, Lucchetti G, Fregnani JHTG, Paiva BSR. Burnout among medical students during the first years of undergraduate school: Prevalence and associated factors. PLoS One. 2018; 13(3):e0191746.

30. Erschens R, Keifenheim KE, Herrmann-Werner A, Loda T, Schwille-Kiuntke J, Bugaj TJ, et al. Professional burnout among medical students: systematic literature review and meta-analysis. Med Teach. 2019;41(2):172-83.

31. Friedberg MW, Cheb PG, Van Busum KR, Aunon F, Pham C, Caloyeras J, et al. Factors affecting physician professional satisfaction and their implications for patient care, health systems, and health policy. Rand Health Q. 2014;3(4):1.

32. Hansell MW, Ungerleider RM, Brooks CA, Knudson MP, Kirk JK, Ungerleider JD. Temporal trends in medical student burnout. Fam Med. 2019;51(5):399-404.

33. NRMP. Charting outcomes in the match. 2014:295. Available from: http:// www.nrmp.org/data/chartingoutcomes2011.pdf.

34. Purvanova RK, Muros JP. Gender differences in burnout: a meta-analysis. J Vocat Behav. 2010;77(2):168-85. https://doi.org/10.1016/j.jvb.2010.04.006.

35. Santen SA, Holt DB, Kemp JD, Hemphill RR. Burnout in medical students: examining the prevalence and associated factors. South Med J. 2010;103(8):758-63.

36. Frajerman A, Morvan Y, Krebs MO, Gorwood P, Chaumette B. Burnout in medical students before residency: a systematic review and meta-analysis. Eur Psychiatry. 2019:55:36-42. https://doi.org/10.1016/j.eurpsy.2018.08.006.
37. McMurray JE, Linzer M, Konrad TR, Douglas J, Shugerman R, Nelson K. The work lives of women physicians: results from the physician work life study. J Gen Intern Med. 2000;15(6):372-80.

38. Shenoi AN, Kalyanaraman M, Pillai A, Raghava PS, Day S. Burnout and psychological distress among pediatric critical care physicians in the United States. Crit Care Med. 2018;46(1):116-22.

39. Shanafelt TD, Gradishar WJ, Kosty M, Satele D, Chew H, Horn L, et al. Burnout and career satisfaction among US oncologists. J Clin Oncol. 2014; 32(7):678-86.

40. Hillhouse JJ, Adler CM, Walters DN. A simple model of stress, burnout and symptomatology in medical residents: a longitudinal study. Psychol Hea Med. 2000;5(1):63-73.

41. Dyrbye LN, Eacker A, Durning SJ, Brazeau C, Moutier C, Massie FS, et al. The impact of stigma and personal experiences on the help-seeking behaviors of medical students with burnout. Acad Med. 2015:90(7):961-9.

42. Fincham JE. Response rates and responsiveness for surveys, standards, and the Journal. Am J Pharm Educ. 2008;72(2):43.

43. Safdar N, Abbo LM, Knobloch MJ, Seo SK. Research methods in healthcare epidemiology: survey and qualitative research. Infect Control Hosp Epidemiol. 2016;37(11):1272-7.

44. Dyrbye LN, Thomas MR, Huntington JL, Lawson KL, Novotny PJ, Sloan JA, et al. Personal life events and medical student burnout: a multicenter study. Acad Med. 2006;81(4):374-84.

45. Cecil J, McHale C, Hart J, Laidlaw A. Behaviour and burnout in medical students. Med Educ Online. 2014;19:25209 Available from: http://www.ncbi. nlm.nih.gov/pubmed/25160716\%0A; http://www.pubmedcentral.nih.gov/ articlerender.fcgi?artid=PMC4145104.

\section{Publisher's Note}

Springer Nature remains neutral with regard to jurisdictional claims in published maps and institutional affiliations.

Ready to submit your research? Choose BMC and benefit from:

- fast, convenient online submission

- thorough peer review by experienced researchers in your field

- rapid publication on acceptance

- support for research data, including large and complex data types

- gold Open Access which fosters wider collaboration and increased citations

- maximum visibility for your research: over $100 \mathrm{M}$ website views per year

At BMC, research is always in progress.

Learn more biomedcentral.com/submissions 